\title{
EL ARTE DE LA FUGA: SUITE FRANCESA ${ }^{1}$
}

THE ART OF FUGUE: FRENCH SUITE

\author{
Lorena Rivera León \\ Universitat de València (España)
}

Recibido: 20-05-2012

Aceptado: 26-06-2012

Resumen: El texto presenta una lectura de Suite francesa de Irène Némirovsky desde la perspectiva de la antropología filosófica. En este sentido, el conflicto bélico sobre el que se construye la novela constituye el marco óptimo desde el que observar la ordenación del universo humano en pares de opuestos mutuamente excluyentes del tipo hombre/mujer, amigo/enemigo, compatriota/ extranjero, noble/plebeyo etc. La narración ofrece asimismo una reflexión sobre las distintas formas de amor, particularmente en lo relativo a eros y ágape.

Palabras-clave: Irène Némirovsky; literatura comparada; antropología filosófica

\begin{abstract}
The text presents an interpretation of Irène Némirovsky's French Suite from the perspective of the Philosophical Anthropology. In this sense, the armed conflict that the novel shows is the ideal framework for observing the human world ordered in mutually exclusive pairs of opposites like man/woman, friend/enemy, compatriot/foreigner, noble/plebeian etc. Additionally, the story offers reflection on the different types of love, particularly on eros and agápe.
\end{abstract}

Key-words: Irène Némirovsky, Comparative Literature, Philosophical Anthropology.

También ellos son hombres. Hasta el ajenjo tiene sus raíces...

Lev Tolstói, Guerra y paz ${ }^{2}$

[1] Quisiera expresar mi gratitud a Miguel Laborda Pemán, porque una tarde luminosa de comienzos de verano me descubrió a Irène Némirovsky entre los estantes de una pequeña librería de Santander; y a mis compañeros del seminario literario en torno a Guerra y paz que los lunes, bajo la batuta de Joan B. Llinares, afinaban sus bien timbradas voces críticas para extraer de la gran epopeya de Tolstói toda la riqueza de sus acentos. Sin ellos mi lectura de esta novela inmensa habría sido sin duda menos vibrante.

[2] Lev Tolstói, Guerra y paz, trad. de Lydia Kúper, Barcelona, Taller de Mario Muchnik/Grup 62/ El Aleph Editores, 2011, p. 1585. 
En el tramo final de Guerra y paz, Petia, que se ha unido al destacamento de Denísov en los estertores de la contienda, se duerme vencido por el cansancio mientras un cosaco le afila el sable. Tan sólo un par de páginas después, la temeridad del pequeño de los Rostov, que ha ingresado en el ejército ruso deseoso de emular las gestas de su hermano mayor Nikolái, lo conducirá a una muerte tan absurda como dramática. Ahora, sin embargo, los silbidos del sable sobre la piedra de afilar suscitan en su imaginación, embargada por el sueño, una melodía nueva y atrayente: "El tema rítmico crecía, pasaba de un instrumento a otro. Era lo que se llama una fuga."3 Al despertar contemplará el último amanecer de su vida. La realidad, que irrumpe en la forma cruel de una bala perdida que le atraviesa el cráneo, dinamita las fantasías de quien, como Don Quijote, había vivido en un reino mágico. ${ }^{4}$

A diferencia de Petia Rostov, Irène Némirovsky, gaseada en Auschwitz por su ascendencia judía el 17 de agosto de 1942, no es un personaje de ficción. No obstante, también su mente creadora parecía subyugada por el esquema tonal de una fuga cuando escribía su ambiciosa novela sobre la ocupación alemana de Francia durante la Segunda Guerra Mundial. El sueño de Irène se concretaba en la misma forma musical que el de Petia. Cada día y durante largas horas, acuclillada a la sombra de un árbol en la campiña de Issy-l'Évêque, llenaba folio tras folio con una letra minúscula por la escasez de papel. No sólo las condiciones materiales de composición del libro eran precarias, sino que el hecho de que tanto a ella como a su marido Michel Epstein -también proveniente de una acaudalada familia de banqueros judíos ucranianos- se les hubiera negado la nacionalidad francesa, hacía especialmente vulnerable a la familia al desastre en una Francia tomada por los invasores nazis. Por ello sorprende que Irène Némirovsky fuera capaz de hallar el sosiego y la concentración necesarios para redactar una obra tan compleja, cuya gestación, aunque abortada, adquiere así tintes heroicos. Efectivamente, Irène Némirovsky no pudo culminar su proyecto de sacar a la luz una gran epopeya de carácter intimista, inspirada en Guerra y paz, ${ }^{5}$ que habría debido ocupar unas mil páginas divididas en cinco partes. El 13 de julio de 1942 fue detenida e internada en el

[3] Ibid., p. 1523.

[4] Cf. Ibid., p. 1522. Parece bastante obvio en este punto el homenaje de Tolstói a Don Quijote de la Mancha, con referencias que traen irremediablemente a la memoria del lector el recuerdo de los episodios cervantinos de la cueva de Montesinos, los molinos de viento o la venta de Maritornes.

[5] En un artículo dedicado a Suite francesa en El País, Mario Vargas Llosa destaca cómo la influencia de Tolstói está presente en esta obra: "Irène Némirovsky tenía al Tolstói de Guerra y paz como modelo cuando escribía su novela." Mario Vargas Llosa, "Bajo el oprobio", en El País, 22/08/2010. http://elpais.com/diario/2010/08/22/opinion/1282428012_850215.html. Por otra parte, en las notas preparatorias de la autora hay explícitas referencias a Tolstói: cf. Irène Némirovsky, Suite francesa, trad. de José Antonio Soriano Marco, Barcelona, Salamandra, 2005, pp. 428, 432, 434.

THÉMATA. Revista de Filosofía, Nº48 julio-diciembre (2013) pp.: 153-164 doi: 10.12795/themata.2013.i48.13 
campo de Pithiviers, para ser posteriormente trasladada a Auschwitz, donde la asesinarían un mes después. Su marido correría la misma suerte en otoño, resultando infructuosos todos sus esfuerzos por dar con el paradero de Irène y conseguir su liberación. Las dos hijas del matrimonio pudieron escapar del acecho de la gendarmería francesa gracias a la protección de su tutora, que las fue ocultando durante varios años en los más diversos lugares, desde conventos a establos o casas de amigos. De lo contrario, habrían encontrado idéntico destino trágico que sus progenitores. En su constante huida las acompañó siempre una maleta que contenía, entre otros documentos, fotografías y algunas joyas, la novela inconclusa en que su madre estaba trabajando antes de su arresto. Pero durante décadas ni Denise ni Élisabeth se atrevieron a leer aquel cuaderno de apretada caligrafía, convencidas de que se trataba de un diario personal de contenido demasiado doloroso para ellas. Por fin, Denise Epstein emprendió la tarea de descifrar con ayuda de una lupa la letra abigarrada de su madre y de mecanografiar el manuscrito antes de entregarlo al Institut Mémoires de l'Édition Contemporaine. En 2004 se publicó, convirtiéndose de inmediato en la primera obra de un autor fallecido a la que se le concedía el prestigioso premio Renaudot.

Pese a que Irène Némirovsky sólo pudo completar dos de las cinco partes de que debería haber constado su novela, logró dotarla del carácter de una auténtica fuga en el sentido polifónico de este tipo de composición musical. Estamos ante una estructura arquitectónica perfecta cuyo armazón lo constituyen pedazos de distintas biografías, las de los personajes que deambulan por sus páginas, hábilmente combinados en contrapunto. Columnas imposibles que desafían a la gravedad porque los angulosos recovecos de sus almas las alejan casi siempre de la línea recta, las voces, no sólo de los protagonistas, sino también de las decenas de secundarios que la autora pone en escena, sostienen en equilibrio los dos movimientos de esta suite. El fragor de las grandes batallas y los alaridos, dolorosos o animosos, de los combatientes, alcanzan el centro de la narración tan sólo como un eco diluido, que conserva no obstante la fuerza necesaria para hacer que los cimientos de la cotidianeidad se tambaleen. Irène Némirovsky dejaba claro su interés por la intrahistoria en sus notas preparatorias: "Lo más importante aquí, y lo más interesante, es lo siguiente: los hechos históricos, revolucionarios, etc., sólo hay que rozarlos, mientras se profundiza en la vida cotidiana y afectiva, y, sobre todo, en la comedia que eso ofrece." ${ }^{6}$ Quizá su determinación en este punto fuera firme por haber aprendido de Tolstói que:

Entretanto, la vida seguía adelante; la verdadera vida de los hombres, con sus intereses sustanciales de salud y enfermedad, de trabajo y descanso; con sus inquietudes intelectuales por la ciencia, la poesía y la música, el amor, la amistad, el odio, las pasiones. Esa

[6] Irène Némirovsky, op. cit., p. 435.

THÉMATA. Revista de Filosofía, No 48 julio-diciembre (2013) pp.: 153-164 doi: 10.12795/themata.2013.i48.13 
vida seguía como siempre, independientemente y al margen de la amistad política o de la hostilidad hacia Napoleón Bonaparte y de todas las reformas posibles. ${ }^{7}$

Esa vida imparable, envuelta en el lejano rumor de la artillería, es la que se despliega en las más de cuatrocientas páginas de Suite francesa. Extremadamente cuidado en la evocación de los sonidos, el libro arranca con un estruendo: el del bombardeo sobre las calles de París. Alertada por el rugir de las alarmas que anunciaban la cercanía de los aviones enemigos, "la gente bajaba la voz instintivamente, como si todo se hubiera poblado de ojos y oídos enemigos. Se oían puertas cerrándose una tras otra. [...] mientras que los ricos preferían quedarse en las porterías, con el oído atento a los estallidos y las explosiones que anunciarían la caída de las bombas". ${ }^{8}$ El relato prosigue en clave auditiva, subrayando la coexistencia de la guerra, que irrumpe amenazando el discurrir tranquilo de los acontecimientos, con la vida que continúa su ciclo imperturbable de nacimientos y muertes:

Se oían cañonazos bastante lejanos, pero, a medida que se acercaban, todos los cristales temblaban en respuesta. En habitaciones cálidas con las ventanas cuidadosamente tapadas para que la luz no se filtrara fuera, nacían criaturas, y su llanto hacía olvidar a las mujeres el aullido de las sirenas y la guerra. En los oídos de los moribundos, los cañonazos parecían débiles y carentes de significado, un ruido más en el siniestro rumor que acoge al agonizante como una ola. Acurrucados contra el cálido costado de sus madres, los pequeños dormían apaciblemente, chasqueando la lengua con un ruido parecido al del cordero al mamar. ${ }^{9}$

Cierra el primer capítulo de la novela un texto que une a la maestría en el dominio de las resonancias sonoras una idea omnipresente en la prosa de Tolstói, quien a su vez la toma prestada de Rousseau, y que reaparecerá en distintos momentos de Suite francesa. Me refiero a una concepción idílica de la naturaleza, cuya belleza y orden fijos se contraponen al caos de la vida humana en sociedad y al horror que ésta puede llegar a suponer, especialmente en el contexto de un conflicto bélico:

El sol, muy rojo todavía, ascendía hacia un cielo sin nubes. De pronto, un cañonazo sonó tan cerca de París que los pájaros abandonaron lo alto de todos los monumentos. Grandes pájaros negros, invisibles el resto del tiempo, planeaban en las alturas, extendiendo al sol sus alas escarchadas de rosa; luego llegaban los hermosos palomos, gordos y arrulladores, y las golondrinas, y los gorriones, que brincaban tranquilamente por las calles desiertas. A orillas del Sena, cada álamo tenía su racimo de pajarillos pardos que cantaban con todas sus fuerzas. En el fondo de los subterráneos se oyó al fin una llamada muy lejana, amortiguada por la distancia, una especie de diana de tres tonos. La alerta había acabado. ${ }^{10}$

[7] Lev Tolstói, op. cit., p. 609.

[8] Irène Némirovsky, op. cit., p. 30

[9] Ibid., pp. 30-31.

[10] Ibid., p. 31.

THÉMATA. Revista de Filosofía, Nº48 julio-diciembre (2013) pp.: 153-164 doi: 10.12795/themata.2013.i48.13 
La primera parte de Suite francesa, que lleva por título Tempestad en junio, es un fresco repleto de matices del éxodo de París tras el inicio de los bombardeos alemanes sobre la ciudad. Se trata de un retrato coral con gran cantidad de personajes. En su plan inicial, Irène Némirovsky preveía que algunos de ellos fueran reapareciendo a lo largo del libro, como de hecho ocurre ya en Dolce, segunda parte de la narración que su autora sí pudo terminar de redactar y en la que, con mayor economía de caracteres, describe la convivencia forzosa entre las tropas de ocupación alemanas y los habitantes franceses del pueblo de Bussy. Mediante pinceladas precisas, la escritora dibuja en su novela un cuadro descarnado de las grandezas y miserias de que son capaces los seres humanos en situaciones extremas. Dota así de plasmación plástica a una idea expresada por Lucile, la protagonista femenina de Dolce:

Todos sabemos que el ser humano es complejo, múltiple, contradictorio, que está lleno de sorpresas, pero hace falta una época de guerra o de grandes transformaciones para verlo. Es el espectáculo más apasionante y el más terrible del mundo. El más terrible porque es el más auténtico. Nadie puede presumir de conocer el mar sin haberlo visto en la calma y en la tempestad. Sólo conoce a los hombres y las mujeres quien los ha visto en una época como ésta. Sólo ése se conoce a sí mismo. ${ }^{11}$

En la pintura que Irène Némirovsky nos presenta en Tempestad en junio, la luminosidad la aporta principalmente el matrimonio Michaud. Empleados de banca y con un hijo, Jean-Marie, en el frente, ponen cuidadosamente a resguardo en el piso de París, que han de abandonar, sus bienes más preciados, sobre todo libros y fotografías. Convencidos de que nada puede equiparlos mejor para el viaje que la compañía del otro amado, no llevan consigo más que lo imprescindible: algo de ropa de repuesto, artículos de aseo y la foto de un Jean-Marie niño colocada con mimo en el fondo de la maleta. En evidente contraste con ellos tenemos a la familia Péricand, ricos burgueses que acarrean con todo lo que pueden, desde un mullido colchón, sábanas bordadas u objetos de plata hasta los termos de la merienda o las botellas de leche de los niños. En una escena grotesca, habiendo perdido ya todas sus pertenencias durante la huida, a excepción de las joyas y el dinero, pero confiando en recuperar la abundancia en una casa familiar en Nimes, la señora Péricand olvidará a su suegro en la última etapa del camino. En la zona más oscura del cuadro habita Charles Langenet, ese ser que "no amaba nada, al menos nada vivo que el tiempo pudiera alterar y la muerte llevarse"12 y a quien la guerra sólo puede romperle sus preciosas porcelanas, que empaqueta con meticulosidad obsesiva. Situado en el nivel moral más bajo, no duda en engañar a una pareja de recién casados para robarles gasolina. Muere, con cierta justicia poética, atropellado accidentalmente por la corista Arlette Corail, otra moradora de las tinieblas,

[11] Ibid., p. 410.

[12] Ibid., p. 224.

THÉMATA. Revista de Filosofía, № 48 julio-diciembre (2013) pp.: 153-164 doi: 10.12795/themata.2013.i48.13 
superviviente nata más allá de cualquier cuestionamiento ético, que, sin pestañear siquiera, lo abandona como a un perro en mitad de la calle. Oscilando entre la luz y la sombra encontramos al fatuo escritor Gabriel Corte y a su amante Florence, así como a dos de los hijos de la señora Péricand. Tenemos, en primer lugar, al pequeño Hubert, heredero del Petia de Guerra y paz, deseoso, al igual que él, de combatir en el ejército, hasta el punto de escaparse de noche para conseguir su objetivo. Su candor infantil y su indignación frente a la injusticia nos recuerdan también a la joven Natasha Rostov que logró que sus padres descargaran de los carros dispuestos para la huida de Moscú todos sus enseres personales a fin de que se acomodara en ellos a los heridos. Gracias a su mediación, los soldados se libraron de caer prisioneros de las tropas napoleónicas que habrían de ocupar en breve la capital del Imperio. ${ }^{13}$ Hubert es sin duda un personaje prevalentemente positivo que, por su corta edad, representa de algún modo la esperanza del futuro. En contraposición con su frescura, su hermano mayor, el sacerdote Philippe, aparece como un hombre complejo y escindido porque su carácter soberbio y engreído no casa con su propósito de servicio y entrega al prójimo, a quien no puede dejar de ver por debajo de sí mismo. Experimenta un placer casi morboso al coleccionar almas redimidas, pero su incapacidad de representarse a esas personas como iguales, tal y como le correspondería a un buen cristiano, le produce una frustración insoportable. Halla la muerte más brutal y desagradable de toda la novela a manos de un grupo de huérfanos a quienes trata de poner a salvo en medio del conflicto bélico. Recobrada una libertad cuya existencia ya habían olvidado, la masa de adolescentes parece trocarse en una jauría de lobos que lo atacan "con redoblada saña, como locos, como bestias, como si hubieran perdido todo rasgo humano,"14 apedreándolo inmisericordes hasta que agoniza.

En Dolce reciben un tratamiento nuevo algunas de las tesis a las que Irène Némirovsky ya había prestado atención en Tempestad en junio. Es el caso de la idea de que la guerra no sólo plantea la clásica oposición en términos de amigo/ enemigo o compatriotas/extranjeros, sino que hace que emerja completamente hasta la superficie, extremándolo, todo aquello que ya de manera habitual separa a los seres humanos, en virtud de su poder adquisitivo, educación, procedencia social o nacimiento, en ricos/pobres, nobles/plebeyos, urbanitas/campesinos u hombres/mujeres. Quienes poseen dinero e influencias, como Gabriel

[13] "Aquella gente que negaba un vaso de agua o una cama a los refugiados, los que se hacían pagar los huevos a precio de oro, los que llenaban el coche de maletas, de paquetes, de comida, hasta de muebles, y respondían a una mujer muerta de cansancio: 'No podemos llevarla. Ya ve que no hay sitio...' Aquellas maletas de cuero leonado y aquellas mujeres maquilladas en un camión lleno de oficiales... Tanto egoísmo, tanta cobardía, tanta crueldad feroz y vana le revolvían el estómago." (I. Némirovsky, op. cit., p. 114). Es difícil que estas palabras de Hubert no traigan a la memoria del lector las páginas de Guerra y paz a las que me he referido. Cf. L. Tolstói, op. cit., pp. 1243-1252.

[14] Irène Némirovsky, op. cit., p. 182.

THÉMATA. Revista de Filosofía, Nº48 julio-diciembre (2013) pp.: 153-164 doi: 10.12795/themata.2013.i48.13 
Corte y su amante, pueden procurarse una comida apetitosa e incluso un techo bajo el que cobijarse aun cuando todas las vías de aprovisionamiento parezcan cerradas y los alojamientos completos. Cuando al final de su huida los Corte llegan al Grand Hôtel, Florence mantiene una reveladora conversación con la doncella que le han asignado, que pone de manifiesto cómo ni siquiera una experiencia tan traumática como la de la guerra ha conseguido aproximar esos dos mundos que siempre se mantuvieron separados:

- Después de lo que hemos pasado, es comprensible... La señora debería echar un sueñecito.

- Imposible... En cuanto cierro los ojos, vuelvo a oír las bombas, a ver esos puentes, esos muertos...

- La señora lo olvidará.

- ¡Ah, no, eso nunca! ¿Podrías olvidarlo tú?

- Mi caso es distinto.

- ¿Por qué?

- ¡La señora tiene tantas cosas en que pensar! -dijo Julie. ${ }^{15}$

Benoît Labarie, un campesino cerril hecho prisionero durante la guerra, que regresa a su hogar en Bussy tras haber logrado fugarse, no soporta al oficial Kurt Bennot, el intérprete alemán al que ha de alojar durante la ocupación y a quien acabará asesinando. Es éste un joven extremadamente culto, en el que nace una simpatía inmediata hacia Madeleine, la esposa de Benoît. Esta inclinación favorable hacia su anfitriona se debe a que, la primera vez que la ve, está sentada en una sillita baja amamantando a su hijo en mitad de una estancia lúgubre y húmeda, de gastadas baldosas rojizas; imagen que a él le trae a la memoria uno de esos interiores de la escuela flamenca que ha contemplado extasiado en los museos de Múnich o Dresde. Esa circunstancia le procura un placer que es a la vez sensual y estético y a partir de ese momento nunca podrá ver como hostil a la muchacha que ha surgido ante él reluciendo en la penumbra con un pecho semidesnudo, como si se hubiera fugado de un lienzo holandés. ${ }^{16}$ Benoît lo odia, no tanto por su condición de enemigo o de extranjero, como por los celos que le provoca pensar que Madeleine pueda sentirse atraída por un "señorito". Así le sucedió de hecho ya una vez durante su ausencia. Fue con Jean-Marie, el hijo de los Michaud herido en combate, francés y por tanto compatriota, a quien las mujeres de la casa cuidaron mientras estuvo convaleciente. También en este caso una diferencia social y cultural parece

[15] Ibid., p. 199.

[16] Cf. ibid., pp. 268-276. Mientras que la granja de los Labarie es para Kurt Bennot como un "interior" de escuela flamenca, el teniente Bruno von Falk, alojado en casa de Lucile, no puede dejar de ver ese lugar como surgido de una novela de Balzac. (cf. Ibid., pp. 297, 326). Todo sucede pues como si, de acuerdo con la tesis de Edward W. Said, la literatura y el arte fueran un filtro del que nos resulta imposible prescindir cuando hemos de asimilar "lo otro" o "al otro". (Cf. Edward W. Said, Orientalismo, trad. de Maria Luisa Fuentes, Barcelona, Mondadori, 2003; Íd., Cultura e imperialismo, trad. de Nora Catelli, Barcelona, Anagrama, 2004).

THÉMATA. Revista de Filosofía, $\mathrm{N}^{\circ} 48$ julio-diciembre (2013) pp.: 153-164

doi: 10.12795/themata.2013.i48.13 
más fuerte que cualquier oposición surgida a raíz del enfrentamiento armado.

En cuanto al par hombre/mujer, la guerra parece haber asignado papeles bien diferenciados a ambos sexos, como así lo recuerda Bennot citando palabras del Zaratustra de Nietzsche: "El hombre ha nacido para ser guerrero, como la mujer para el descanso del guerrero." ${ }^{17} \mathrm{Si}$ el bramido de la artillería queda asociado a la presencia masculina en la batalla, las mujeres, ya desde los tiempos en que la paciente Penélope esperaba el regreso de Ulises en la Odisea, tienen en la fricción metálica de las agujas de hacer punto el acompañamiento musical por excelencia en periodos de contienda. Con "las manos como erizos plateados, agujas yendo y viniendo", ${ }^{18}$ en palabras de Julio Cortázar, Natasha teje, en Guerra y paz, atenta junto a la cabecera del lecho de su amado Andréi agonizante: "Permanecía sentada en la butaca, de perfil a él, ocultándole la luz de la vela, y tejía una media. (Había aprendido a tejer desde que una vez el príncipe Andréi le dijo que nadie cuidaba mejor a los enfermos que las viejas niñeras que hacían punto, y que aquel trabajo resultaba sedante para el enfermo.)" ${ }^{19}$ En Suite francesa, las ruecas, arrumbadas en los graneros desde la anterior guerra, se desempolvan "porque ahora todas las chicas de la región aprendían a hilar la lana, puesto que ya no podía comprarse en madejas..." ${ }^{20}$ Sin embargo, curiosamente sólo las ancianas matan el tiempo haciendo punto, ${ }^{21}$ pues aguardar guardándose no parece ser ya la consigna de las más jóvenes.

Entramos con esta última observación en el que es, a mi modo de ver, uno de los núcleos temáticos más interesantes de Suite francesa. Según la vivencia de Lucile y el teniente Bruno von Falk, que se enamoran en Dolce contraviniendo todas las normas morales establecidas, existe un conflicto entre el individuo y la sociedad, que se exacerba hasta lo insoportable cuando hay guerra, ya que ésta es la "obra común por excelencia"22 en aras de la cual se admite el sacrificio de los individuos. Bruno llega a hablar de un "espíritu de la colmena" por el que los humanos obedecen a fines que les son desconocidos y del que Lucile quiere sustraerse a toda costa, siendo su deseo "elegir mi propio camino, mantenerme en él, no seguir al enjambre." ${ }^{23}$ Lo que su amor les muestra a estos dos jóvenes de países enfrentados; a él, invasor, y a ella, residente

[17] Ibid., p. 275.

[18] Julio Cortázar, "Casa tomada”, en Íd., La isla a mediodía y otros relatos, Barcelona, Salvat, 1982 , p. 116.

[19] Lev Tolstói, op. cit., p. 1416.

[20] Irène Némirovsky, op. cit., p. 270.

[21] Cf. ibid., pp. 95, 110, 126, 298.

[22] Ibid., p. 328.

[23] Ibid., p. 367. Cf. ibid., pp. 328-329. En la misma línea se encuentra esta cita: "Bruno pensó que buscaba lo que todos los seres humanos, la felicidad, el libre desenvolvimiento de sus facultades, y que ese legítimo deseo se veía continuamente contrariado por una especie de razón de Estado llamada guerra, seguridad pública, necesidad de preservar el prestigio del ejército vencedor.” (Cf. ibid., p. 391)

THÉMATA. Revista de Filosofía, Nº48 julio-diciembre (2013) pp.: 153-164 doi: 10.12795/themata.2013.i48.13 
en territorio ocupado, es que el individuo y la comunidad a la que supuestamente aquél pertenece y en la que debería sentirse integrado, no comparten necesariamente idénticos odios y afectos. Esta misma experiencia la tienen, aunque con menor intensidad, un buen número de franceses y alemanes que, con el tiempo, acaban por conocerse por sus nombres, hasta el punto de que los primeros llegarán a preguntarse si extrañarán al ejército ocupante tras su marcha: "¿Los echarían de menos? No en tanto que alemanes, en tanto que invasores, claro (ninguno era tan ingenuo para planteárselo así); pero ¿echarían de menos a aquellos Paul, Siegfried, Oswald, que habían vivido tres meses bajo sus techos, que les habían enseñado fotos de sus mujeres o sus madres, que habían bebido con ellos más de una botella de vino...?"24 En contraposición con ellos están quienes, como la suegra de Lucile, son incapaces de ver en el enemigo a un ser humano, asimilándolo a un demonio o a su idea de lo monstruoso, por ejemplo en la forma de un caníbal:

Para la señora Angellier, un alemán no era un hombre, sino la personificación de la maldad, la crueldad y el odio. Que otros tuvieran una opinión distinta le parecía imposible, inconcebible... Era tan incapaz de imaginarse a Lucile enamorada de un alemán como de representarse el acoplamiento de una mujer y un unicornio, un dragón, una quimera... El alemán tampoco le parecía enamorado de Lucile, porque no podía atribuirle ningún sentimiento humano." ${ }^{5}$

Pese a la falta de imaginación de la señora Angellier, la realidad es que no sólo Lucile y Bruno, sino muchos otros jóvenes enemigos según las reglas del conflicto bélico, se enamoran o al menos flirtean en la novela. De acuerdo con J. Glenn Gray: "A los hombres y las mujeres arrastrados en el tiempo y el espacio por los avatares de la guerra, no les queda otra reacción que el encontrar amores temporales y verter en ellos todas sus ansias de belleza, ternura y encanto." ${ }^{26}$ La vida sigue su curso y "para aquellas chicas, el verano de 1940

[24] Ibid., p. 405.

[25] Ibid., pp. 348-349. Véanse también ibid., pp. 263, 275: “- Y... ¿lle gusta esa vida? -preguntó Madeleine con fingida candidez, pero sintiendo un leve estremecimiento de repugnancia, como si le hubiera preguntado a un caníbal: ‘Es verdad que le gusta la carne humana?”

[26] J. Glenn Gray, Guerreros. Reflexiones del hombre en la batalla, trad. de Mónica Garrido y prólogo de Hannah Arendt, Barcelona, Inèdita Editores, 2004, p. 97. El 8 de mayo de 1941 Jesse Glenn Gray recibió la orden de reclutamiento para luchar durante la Segunda Guerra Mundial en el mismo correo que le trajo la noticia de que la Universidad de Columbia le había otorgado su Doctorado en Filosofía. El 28 de octubre de 1945 se licenció con honores como segundo teniente, tras cuatro años de servicio. Una vez finalizada la guerra, y fundamentalmente durante un largo periodo pasado en Alemania gracias a una beca, escribió Guerreros, libro en el que medita sobre su experiencia en combate usando en parte como material de base fragmentos del diario personal que llevó consigo durante el tiempo en que fue miembro del ejército aliado. Su experiencia con civiles en Italia, Francia y Alemania, además de con otros soldados, hacen que sus reflexiones resulten especialmente pertinentes en relación con Suite francesa. Véanse a este respecto las siguientes páginas: 35-36, 87, 96-109, 172-173, 179.

THÉMATA. Revista de Filosofía, № 48 julio-diciembre (2013) pp.: 153-164 doi: 10.12795/themata.2013.i48.13 
sería, en su recuerdo y pese a todo, el verano de sus 20 años". ${ }^{27}$

El enamoramiento de Bruno y Lucile, aunque acaba en fracaso, posee un interés y encanto particulares, porque su avance gradual nos permite observar cómo poco a poco van venciéndose todas las dificultades que imponen los prejuicios sociales. Al principio, Lucile no puede dejar de torturarse con la idea de que es incluso factible que el teniente Von Falk en persona haya hecho prisionero a su marido Gaston, con el que mantiene un matrimonio infeliz. Lo cierto es que "un soldado enemigo nunca parecía estar solo - un ser humano frente a otro ser humano-, sino acompañado, rodeado por un innumerable ejército de fantasmas, el ejército de los ausentes y los muertos. No se hablaba con un hombre, sino con una muchedumbre invisible." 28 Además, "por más que lo intentara, no podía atribuirle las reflexiones, los deseos naturales de un individuo normal." ${ }^{29}$ Gradualmente, sin embargo, empieza a sentirse atraída por ese extranjero en el que percibe todavía algo salvaje que le produce temor, ${ }^{30}$ a pesar de que él ya ha conseguido, de manera involuntaria, que se resquebraje la coraza defensiva de la joven con un recurso precisamente musical: tocar el piano. La escena en que esto ocurre está tan lograda que merece una mención. He aquí cómo en el corazón de Lucile comienza a anidar el deseo: "La guerra y el desastre de 1940 no serán más que un recuerdo, una página de la Historia, nombres de batallas y tratados que los estudiantes recitarán en los institutos. Pero yo recordaré este ruido sordo de botas golpeando el suelo mientras viva.", se dice al escuchar los pasos del teniente Von Falk que alteran la tranquilidad de la noche. Con el oído atento percibe "el siseo del sifón de agua de Selz y el débil chss-chss de un limón exprimido", por lo que deduce que está bebiendo. A continuación, reconoce el golpe seco de la tapa del piano al abrirse y el chirrido del taburete que gira. Bruno va a tocar y su ejecución resulta de un erotismo delicado y anhelante, con culminación orgásmica: "Sí, estaba tocando. Lucile escuchó con la cabeza baja, mordiéndose nerviosamente el labio inferior. No fue tanto un arpegio como una especie de suspiro que ascendía del teclado, una palpitación de notas; las rozaba, las acariciaba, y acabó con un trino leve y rápido como el canto de un pájaro. Luego, todo quedó en silencio." Lucile, sola en su cuarto, manteniéndose muda le responde con la elocuencia de su cuerpo: el pelo suelto le cae sobre los hombros y tiene el cepillo en la mano. No nos cuesta imaginar su labio inferior aún enrojecido por los mordiscos: "Al fin, suspiró y

[27] Irène Némirovsky, op. cit., p. 168. Véanse asimismo ibid., pp. 256-257, 308.

[28] Ibid., pp. 258-259.

[29] Ibid., p. 265.

[30] "Casi estaba asustada de los sentimientos que empezaban a despertar en su interior, no muy distintos de los que habría experimentado al acariciar a un animal salvaje, una sensación áspera y deliciosa, una mezcla de enternecimiento y terror. [...] Cuando hablaba en alemán, sobre todo en aquel tono de mando, su voz adquiría una sonoridad vibrante y metálica que producía a los oídos de Lucile un placer similar a un beso dado con rabia y acabado en mordisco.” Ibid., pp. 340-341.

THÉMATA. Revista de Filosofía, Nº48 julio-diciembre (2013) pp.: 153-164 doi: 10.12795/themata.2013.i48.13 
pensó vagamente: 'Lástima...' (¿Lástima que el silencio fuera tan profundo? ¿Que quien estaba allí fuera él, el invasor, el enemigo, y no otro?) Hizo un leve gesto de irritación con la mano, como si apartara capas de aire demasiado denso, irrespirable. Lástima... Y se acostó en la gran cama vacía.” ${ }_{11}$

Lucile, enamorada, se mira al espejo y empieza a dialogar con "una parte de sí misma que hasta entonces desconocía, una parte invisible que veía por primera vez, una mujer de ojos negros, labios finos y temblorosos y mejillas encendidas, que era ella y no lo era del todo." ${ }^{32}$ Esa nueva claridad con respecto a sí misma es fruto del amor erótico que encuentra en Bruno, porque, si bien las facciones humanas pueden difuminarse hasta su disolución entre una multitud anónima que ya no es sino manada animal si atendemos al ágape, a la caridad o amor compasivo; ${ }^{33}$ el eros, en cambio, aun en las condiciones más adversas, rescatará siempre la humanidad en el rostro irremplazable del amado. La ceguera implícita en una catalogación abstracta de quienes percibimos como diferentes y ajenos, únicamente encuentra su cura en la lucidez que devuelven los ojos del amante.

"A un lado estamos él y yo, y al otro la gente", ${ }^{34}$ afirma en Suite francesa una costurera de Bussy que padece la inquina de sus convecinos por haberse enamorado de un soldado alemán, al igual que les sucediera a tantas otras jóvenes a lo ancho de Europa durante la Segunda Guerra Mundial. Como señala J. Glenn Gray: "En la mayoría de los casos, la propia chica no apoyaba ni la nación alemana, ni su política en Francia. Sentía que ella misma era una apasionada defensora de los ideales franceses y de la democracia francesa. Pero... su amante era diferente. No pertenecía al odiado enemigo, aunque llevase su uniforme, hablase su idioma y estuviese obligado a acatar sus órdenes. Su alma no era extranjera, no había sido contagiada por algo ajeno y hostil, pues le pertenecía exclusivamente a ella." 35 Sólo en un "tú y yo" puede el "nosotros y los otros" hallar su feliz superación y la paz albergar esperanzas de triunfo futuro, pues: ${ }^{36}$

[31] Ibid., p. 267. Todas las citas entrecomilladas corresponden a esta página.

[32] Ibid., p. 368.

[33] Frente al amor, la caridad, que no se dirige en principio a un individuo en concreto, sino a la humanidad en general como concepto abstracto, puede fracasar en momentos de grandes crisis, como lo muestra el siguiente pasaje de Suite francesa: "Había demasiados refugiados. Había demasiados rostros cansados, demacrados, sudorosos; demasiados niños llorando, demasiados labios temblorosos que preguntaban: ‘No sabrá usted dónde podríamos encontrar una habitación o una cama?' ‘Podría usted indicarnos un restaurante, señora?’ Era como para desalentar la caridad. Aquella multitud miserable ya no presentaba rasgos humanos; parecían una manada en estampida. Una extraña uniformidad se extendía sobre ellos.” Ibid., p. 78.

[34] Ibid., p. 321.

[35] J. Glenn Gray, op. cit., p. 100.

[36] J. Glenn Gray comenta a este propósito que: "todo el que haya aprendido a pensar de forma concreta no odiará de forma abstracta, o por lo menos, no por mucho tiempo. Ésta es la única ima-

THÉMATA. Revista de Filosofía, № 48 julio-diciembre (2013) pp.: 153-164

doi: 10.12795/themata.2013.i48.13 
En el corazón de cada hombre y de cada mujer pervive una especie de paraíso en el que la muerte y la guerra no existen, en el que los lobos y las ciervas juegan en paz. Sólo hay que descubrirlo, sólo hay que cerrar los ojos a todo lo demás. Somos un hombre y una mujer. Nos amamos. ${ }^{37}$

El 8 de diciembre de 1944, J. Glenn Gray hacía en su diario de guerra la siguiente anotación: "si quiero sobrevivir a esta época tengo que amar más. No hay otra manera..." "38 Irène Némirovsky no sobrevivió a su época; no se lo permitieron. Su novela, inconclusa, se cierra sin embargo, de manera casi mágica, en círculo. Como al comienzo, la guerra fuerza a una masa humana a ponerse en movimiento: los alemanes, llamados al combate en Rusia, se ven obligados a abandonar el pueblo. La cocina de campaña, errático vestigio del hogar que una vez tuvieron y que aún les aguarda muy lejos, va con ellos "traqueteando al final de la comitiva como una cacerola atada a la cola de un perro." ${ }^{39}$ Acabada su misión, los soldados parten entonando un himno grave y lento que se pierde en la noche. No han logrado apresar al fugitivo Benoit, que ha escapado, con ayuda de Lucile, camino de París. Irène Némirovsky, sin embargo, no pudo evadirse de sus verdugos. Cazada prácticamente cuaderno en mano, se afanó casi hasta el hálito postrero para insuflar de vida a sus criaturas. Generosa con un personaje mezquino, le brindó a Benoît la posibilidad de una huida que se negó a sí misma para dar a luz esa fuga del arte poético que es, ya desde su mismo título de ecos bachianos, un canto a la música, tal vez "porque sólo la música es capaz de abolir las diferencias de idioma o costumbres de dos seres humanos y tocar algo indestructible en su interior." ${ }^{40}$

gen que nos proporciona grandes esperanzas para el futuro.” Ibid., pp. 185-186.

[37] Irène Némirovsky, op. cit., p. 395.

[38] J. Glenn Gray, op. cit., p. 228.

[39] Irène Némirovsky, op. cit., p. 414.

[40] Ibid., p. 381.

THÉMATA. Revista de Filosofía, Nº 48 julio-diciembre (2013) pp.: 153-164 doi: 10.12795/themata.2013.i48.13 